\title{
PERTIMBANGAN KONSUMEN DALAM PURCHASE DECISION OBAT BEBAS PAINKILLER
}

\author{
Febriyanti ${ }^{1}$ dan Yasintha Soelasih ${ }^{2}$ \\ 1 Jurusan Manajemen, Fakultas Bisnis dan Ekonomi, Universitas Katolik Indonesia Atma Jaya \\ ${ }^{2}$ Fakultas Bisnis dan Ekonomi, Universitas Katolik Indonesia Atma Jaya \\ Email: 1fffynt.rile@gmail.com, 르asintha.soelasih@atmajaya.ac.id
}

\begin{abstract}
ABSTRAK
Penelitian ini bertujuan untuk melihat pertimbangan konsumen dalam purchase decision obat bebas painkiller. Responden yang dipilih untuk mengisi survey ini adalah konsumen yang telah membeli obat bebas painkiller selama 3 bulan terakhir. Sampel diambil dengan menggunakan teknik non-probability sampling dengan purposive sampling. Responden pada penelitian ini berjumlah 175 orang. Penelitian ini menggunakan analisis regresi linier berganda untuk pengujiannya. Hasil dari penelitian ini menunjukkan bahwa promotion, product quality, dan price memberikan pengaruh terhadap purchase decision. Sedangkan, perceived risk tidak memberikan pengaruh terhadap purchase decision.
\end{abstract}

Kata Kunci: obat bebas painkiller, promotion, product quality, price, perceived risk, purchase decision

\begin{abstract}
This study aims to look at consumer considerations in purchase decision over the counter painkiller drugs. The respondents are consumers who have purchased over the counter painkiller drugs for the past 3 months. Samples were taken using non-probability sampling techniques with purposive sampling. Respondents in this study were 175 people. This study uses multiple linear regression analysis for testing. The results of this study indicate that promotion, product quality, and price influence the purchase decision. Meanwhile, perceived risk has no effect on purchase decisions.
\end{abstract}

Keywords: over the counter drugs, promotion, product quality, price, perceived risk, purchase decision

\section{A. PENDAHULUAN}

Pada saat sekarang kebutuhan manusia lebih banyak pada produk kesehatan seperti vitamin, masker, obat-obatan pribadi dan lain-lain. Perubahan ini disebabkan karena adanya pandemi Covid19. Sementara kebutuhan konsumen meningkat terhadap produk kesehatan tertentu yang menyebabkan tingkat permintaan semakin tinggi, tetapi banyak juga produk terutama obat painkiller yang tidak semuanya dibutuhkan oleh konsumen pada saat ini. Bila dilihat data perkembangan farmasi di Indonesia pada gambar 1. Terjadi kenaikan yang tinggi pada tahun 2020 dibandingkan tahun sebelumnya. Hal ini menunjukkan tingginya persaingan farmasi di Indonesia. 


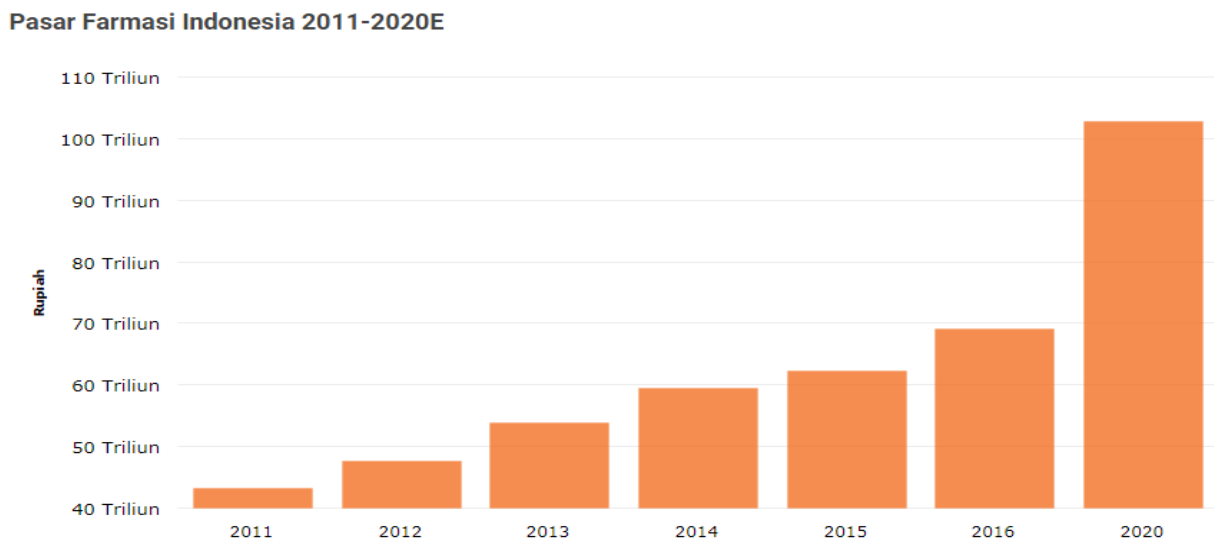

Gambar 1. Prediksi Perkembangan Pasar Farmasi Indonesia Tahun 2020 Sumber: katadata.co.id (2017)

Pada tahun 2019 penjualan produk farmasi OTC mengalami penjualan yang meningkat dan mendominasi perolehan bisnis sebanyak 30\% dan produk onkologi sebanyak $25 \%$ sedangkan sisanya beragam produk kesehatan lainnya (Kontan, 2019). Kasus swamedikasi meningkat karena masyarakat lebih memilih untuk melakukan swamedikasi daripada pergi berobat. Menurut Badan Pusat Statistik (BPS), mayarakat yang melakukan swamedikasi pada tahun 2018 (70.74\%) meningkat dari tahun 2017 (69.43\%). Menurut Hantoro, Pristiany, Athiyah, \& Yuda (2014), keluhan sakit yang paling banyak diderita oleh masyarakat yang melakukan swamedikasi adalah nyeri (76\%).

Melihat sangat besarnya antusias masyarakat terhadap swamedikasi terhadap nyeri, maka perusahaan farmasi banyak beralih kedalam pasar obat bebas. Namun, semakin banyaknya perusahaan farmasi yang mengambil pasar obat bebas painkiller, maka akan semakin banyak pilihan obat nyeri yang dapat dipilih oleh masyarakat. Oleh karena itu, perusahaan farmasi harus memiliki strategi agar dapat memenangkan pertandingan di pasar obat bebas terutama painkiller, dimana obat bebas ini banyak digunakan oleh masyarakat. Maka dari itu, perusahaan harus mampu menjawab kebutuhan masyarakat melalui suatu produk.

Dalam melakukan pembelian obat bebas painkiller ada beberapa faktor yang dapat mempengaruhi yaitu promotion, product quality, price, dan perceived risk. Menurut Brata, Hussani \& Ali (2017), promotion mempengaruhi purchase decision. Penelitian Rahman \& Sitio (2019) menunjukkan purchase decision dipengaruhi promotion. Nugraha, Kusumawardani \& Octavianie (2018), melakukan penelitian pada healthy food diet business dengan menguji pengaruh celebrity endorsement di instagram terhadap customer behavior dan purchase intention. Hasil penelitian Nugraha et al. (2018), menunjukkan bahwa terjadi pengaruh promosi yag dilakukan oleh celebrity endorsement di Instagram terhadap customer behavior dan purchase intention.

Product quality merupakan salah satu faktor yang mempengaruhi purchase decision obat bebas painkiller karena dapat mempengaruhi kinerja dari suatu produk atau 
jasa. Menurut Rahman et al., (2019), product quality memiliki pengaruh terhadap purchase decision. Suhaily \& Darmoyo (2017) juga berpendapat bahwa product quality mempengaruhi purchase decision.

Price merupakan salah satu alat yang dalam memasarkan suatu produk yang digunakan untuk menghadapi pasar dan digunakan untuk menarik klien agar dapat mengambil keputusan pembelian, serta untuk bertarung dengan pesaing di market (Boonlertvanich, 2009). Menurut Djatmiko \&Pradana (2016), price memiliki pengaruh terhadap purchase decision. Brata et al., (2017) dan Suhaily et al., (2017) juga mengungkapkan bahwa price memiliki pengaruh terhadap purchase decision. Namun, Gecit \& Kayacan (2017) memiliki hasil yang berbeda. Menurut Gecit et al., (2017), price memiliki efek negatif pada purchase decision. Yee \& San (2011) berpendapat bahwa adanya hubungan yang positif antara perceived risk dengan purchase decision.

Melihat fenomena yang ada maka dilakukan penelitian untuk melihat bagaimana pertimbangan konsumen dalam purchase decision obat bebas painkiller.

\section{B. TINJAUAN PUSTAKA}

\section{Promotion}

Menurut Kotler, Amstrong, \& Opresnik (2018:78), promotion mengacu pada kegiatan yang mengkomunikasikan keunggulan produk dan membujuk pelanggan untuk membelinya. Dimensi promosi menurut Kotler et al. (2018) adalah advertising, personal selling, sales promotion, public relations, dan direct and digital. Promotion memiliki pengaruh yang signifikan terhadap purchase decision (Syafrida, 2018). Menurut Brata et al. (2017), promotion mempengaruhi purchase decision produk di PT Jaya Swarasa Agung. Hasil penelitian menunjukkan bahwa promotion memiliki hubungan yang sangat tinggi terhadap purchase decision. Promotion dapat menggerakkan konsumen untuk membuat keputusan pembelian dengan cara memberikan informasi mengenai suatu produk, sehingga konsumen dapat terdorong untuk mengambil keputusan melakukan pembelian. Menurut Rares \& Jorie (2015), promotion merupakan kegiatan yang dapat mempengaruhi dan membujuk konsumen agar dapat membeli suatu produk atau jasa sehingga pembelian terhadap suatu produk dapat dilakukan secara terus menerus oleh konsumen. Selain itu, promotion juga dapat meningkatkan penjualan, mempengaruhi konsumen yang memiliki sensitivitas terhadap harga, dan juga mendorong konsumen untuk melakukan pembelian kembali (Huff \& Alden, 2000). Menurut penelitian Brata et al. (2017) dan Rahman et al. (2019), promotion memiliki pengaruh yang signifikan terhadap purchase decision. Berdasarkan dari penelitian terdahulu, maka promotion berpengaruh terhadap purchase decision sebagai hipotesis pertama. 
H1: Promotion berpengaruh terhadap purchase decision obat bebas painkiller.

\section{Product Quality}

Menurut Kotler et al. (2018:249), product quality merupakan karakteristik suatu produk atau jasa dimana kemampuannya sesuai dengan kebutuhan pelanggan. Menurut Orville, Boyd, Larreche, dan Claude (2005:422), agar dapat mempertahankan keunggulan kompetitifnya dalam pasar perusahaan harus mengetahui dimensi yang digunakan untuk menciptakan competitive advantage dibandingkan dengan pesaing. Product quality juga memiliki makna bahwa quality didasarkan pada pengalaman masingmasing konsumen dalam suatu produk atau jasa, artinya kualitas dalam suatu produk hanya dirasakan atau sesuai dengan persyaratan yang telah ditetapkan (Singhdong, 2017). Dalam penelitiannya, product quality memiliki pengaruh yang signifikan terhadap purchase decision (Singhdong, 2017).

Menurut Ginting \& Sembiring (2018), product quality merupakan suatu produk dalam bentuk barang atau jasa yang dapat diukur dalam tingkat kualitas standar, adanya tambahan kesan istimewa, dan fungsional dari produk tersebut dapat memenuhi harapan konsumen. Menurut Rahman et al. (2019) dan Brata et al. (2017) product quality memiliki pengaruh yang signifikan terhadap purchase decision. Menurut Brata et al. (2017), product quality memiliki hubungan dengan purchase decision produk di PT Jaya Swarasa Agung.Product quality merupakan kemampuan suatu produk untuk melakukan fungsinya. Menurut Brata et al. (2017), dalam product quality terdapat 5 dimensi yaitu bentuk, kualitas kerja, daya tahan, dan kesan terhadap kualitas dan desain. Menurut Suhaily et al. (2017), product quality berpengaruh positif dan signifikan terhadap purchase decision produk elektronik brand Jepang. Berdasarkan penelitian-penelitian terdahulu, maka peneliti ingin melihat pengaruh product quality terhadap purchase decision.

H2: Product Quality berpengaruh terhadap purchase decision obat bebas painkiller.

\section{Price}

Price merupakan salah satu elemen dalam pemasaran yang dapat menghasilkan pendapatan. Selain itu, price merupakan salah satu elemen yang paling fleksibel karena sewaktu-waktu dapat berubah. Price memainkan peran kunci dalam menciptakan pelanggan dan membangun hubungan dengan pelanggan (Kotler et al., 2018). Menurut Kotler et al. (2018:308), price merupakan sejumlah uang yang harus dibayarkan oleh pelanggan untuk mendapatkan suatu produk atau jasa. Price dapat menjadi "senjata pamungkas", tetapi dapat juga sebagai pedang bermata dua. Dalam arti lain, price juga memiliki arti sejumlah dari semua nilai yang diberikan pelanggan untuk mendapatkan manfaat memiliki atau menggunakan produk atau jasa. 


\section{Vol : 5 Nomor : 2 September 2020}

Price merupakan salah satu dari biaya yang harus dihadapi oleh konsumen, namun harga juga dapat ditentukan oleh konsumen serta memainkan peran penting dalam pengambilan keputusan untuk pembelian barang atau jasa (Kensei \& Todd 2003). Harga merupakan komponen utama dalam memproses berbagai macam produk dan juga menjadi dasar utama penilaian (Lawson \& Bragat, 2002). Harga yang wajar akan mempengaruhi konsumen dalam melakukan purchase decision (Soelasih, 2014, Suhaily \& Soelasih, 2018)). Menurut Syafrida (2018), price memiliki pengaruh yang signifikan terhadap purchase decision. Menurut Djatmiko \& Pradana (2016), memiliki pengaruh terhadap keputusan pembelian pada smartphone. Selain itu, penelitian Brata et al. (2017) juga menyatakan bahwa price memiliki hubungan dengan purchase decision. Namun lain halnya dengan penelitian Gecit et al. (2017). Menurut Gecit et al. (2017), price memiliki efek negatif pada purchase decision. Berdasarkan penelitian tersebut maka menjadi dasar terbentuknya hipotesis 3.

H3: Price berpengaruh terhadap purchase decision obat bebas painkiller.

\section{Perceived Risk}

Resiko yang dirasakan oleh konsumen merupakan fungsi dari dua faktor umum, yaitu jumlah yang dipertaruhkan dalam keputusan pembelian dan perasaan individu terhadap kepastian subyektif bahwa konsumen akan merasa "beruntung" atau "kehilangan" semua atau sebagian dari jumlah yang telah dikeluarkan (Cox dan Rich, 1964). Namun demikian, konsumen dapat merasakan risiko substansial dari kehilangan waktu (waktu dalam pengembalian dan juga menunda dalam mendapatkan barang yang dibutuhkan), kehilangan dan frustasi (ketidakpuasan akibat melakukan pembelian yang buruk), dan tidak mencapai tujuan pembelian (Cox dan Rich, 1964). Risk memiliki peranan penting dalam hal mempengaruhi perilaku konsumen dan memberikan kontribusi yang berharga dalam keputusan pembelian konsumen (Barnes, 2007).

Menurut Ko, Jung, Kim dan Shim (2010), perceived risk merupakan kemungkinan kehilangan dalam mencapai hasil yang menguntungkan saat konsumen melakukan belanja online. Bauer (1960) memperkenalkan perilaku dalam pengambilan resiko. Sehingga, dapat diartikan sebagai salah satu faktor internal yang kemungkinan kehilangan ataupun mendapat keuntungan dalam melakukan suatu pembelian terhadap barang ataupun jasa. Menurut Yee \& San (2011), adanya hubungan yang positif antara perceived risk dengan purchase decision dalam pasar automobile di Malaysia. Hal ini dikarenakan adanya ketidakpastian yang akan mereka alami saat membeli automobile. Resiko yang ditimbulkan antara lain ketidakcocokan mengenai produk, kinerja yang buruk, dan juga merasa tidak aman saat menggunakannya. Menurut Chen, Yan, \& Fan (2015), resiko dapat juga menjelaskan perilaku pembelian konsumen, jika memiliki resiko yang besar maka semakin kecil kemungkinan konsumen akan membeli kembali. Resiko 
yang akan timbul tentu akan membuat konsumen tidak akan melakukan pembelian. Risiko Berdasarkan dari penelitian terdahulu, maka dibentuklah hipotesis 4.

H4: Perceived risk berpengaruh terhadap purchase decision obat bebas painkiller.

Berdasarkan kajian diatas maka dibuatlah model penelitian sebagai berikut.

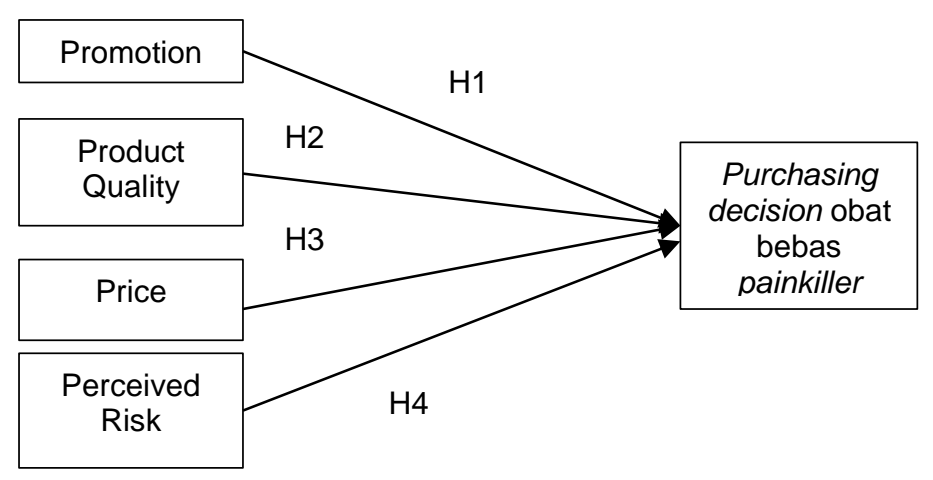

Gambar 2. Model Penelitian

\section{METODE PENELITIAN}

Obyek penelitian adalah konsumen yang membeli obat bebas painkiller. Jumlah populasi tidak diketahui sehingga pada saat menghitung sampel menggunakan jumlah indikator dan variabel dikalikan 10 untuk batas atas dan 5 untuk batas bawah (Hair, William, Banin dan Anderson 2010). Jumlah sampel yang terambil sebanyak 175 dengan cara purposive sampling yang termasuk dalam non-probability sampling. Menurut Sugiyono (2017:218), teknik non-probability sampling merupakan teknik yang tidak memberikan peluang yang sama pada setiap anggota populasi untuk dijadikan sebagai sampel. Pemilihan responden yang dijadikan sampel dengan syarat bahwa mereka melakukan pembelian obat di apotek, toko obat, dan di modern market dalam 3 bulan terakhir dan berusia 17-60 tahun.

Indikator dan variabel yang digunakan dilakukan uji validitas dan reliabilitas. Untuk uji validitas menggunakan confirmatory factor analysis sedangkan reliabilitas menggunakan Cornbach's alpha. Hasil uji validitas terlihat pada tabel 1. 
Vol : 5 Nomor : 2 September 2020

Tabel 1. Uji validitas

\begin{tabular}{|c|c|c|c|c|c|c|c|c|c|c|}
\hline \multirow[t]{2}{*}{$\begin{array}{c}\text { Indicators } N \\
\text { ariabel }\end{array}$} & \multicolumn{2}{|c|}{ Promotion } & \multicolumn{2}{|c|}{ Product Quality } & \multicolumn{2}{|c|}{ Price } & \multicolumn{2}{|c|}{ Perceived Risk } & \multicolumn{2}{|c|}{$\begin{array}{l}\text { Purchasing } \\
\text { Decision }\end{array}$} \\
\hline & $\mathrm{KMO}$ & MSA & $\mathrm{KMO}$ & MSA & $\mathrm{KMO}$ & MSA & $\mathrm{KMO}$ & MSA & $\mathrm{KMO}$ & MSA \\
\hline Promotion & 0.586 & & & & & & & & & \\
\hline Promotion 1 & & 0.589 & & & & & & & & \\
\hline Promotion2 & & 0.626 & & & & & & & & \\
\hline Promotion3 & & 0.665 & & & & & & & & \\
\hline Promotion4 & & 0.518 & & & & & & & & \\
\hline Promotion5 & & 0.572 & & & & & & & & \\
\hline Quality & & & 0,748 & & & & & & & \\
\hline Quality1 & & & & 0.796 & & & & & & \\
\hline Quality2 & & & & 0.722 & & & & & & \\
\hline Quality3 & & & & 0.747 & & & & & & \\
\hline Quality4 & & & & 0.745 & & & & & & \\
\hline Price & & & & & 0.545 & & & & & \\
\hline Price1 & & & & & & 0.832 & & & & \\
\hline Price2 & & & & & & 0.527 & & & & \\
\hline Price3 & & & & & & 0.529 & & & & \\
\hline Risk & & & & & & & 0.658 & & & \\
\hline Risk1 & & & & & & & & 0.749 & & \\
\hline Risk2 & & & & & & & & 0.654 & & \\
\hline Risk3 & & & & & & & & 0.613 & & \\
\hline Decision & & & & & & & & & 0.728 & \\
\hline Decision1 & & & & & & & & & & 0.695 \\
\hline Decision2 & & & & & & & & & & 0.769 \\
\hline Decision3 & & & & & & & & & & 0.803 \\
\hline Decision4 & & & & & & & & & & 0.698 \\
\hline Decision5 & & & & & & & & & & 0.716 \\
\hline
\end{tabular}

Menurut Ghozali (2016), hasil dari analisis faktor konfirmatori menunjukkan bahwa setiap indikator dapat membentuk variabel maupun sub-variabel yang diteliti dengan nilai hasil > 0.5. Hasil tabel 1 menunjukkan nilai KMO dan MSA diatas 0.5 artinya semua variabel yang digunakan valid.

Hasil uji reliabilitas terlihat pada tabel 2.

\section{Tabel 2. Uji Reliabilitas}

\begin{tabular}{cc}
\hline Variabel & Cronbach's Alpha \\
\hline Promotion & 0.776 \\
Product Quality & 0.713 \\
Price & 0.701 \\
Perceived Risk & 0.776 \\
Purchase Decision & 0.776 \\
\hline
\end{tabular}


Menurut Ghozali $(2016,48)$ untuk mendapatkan skala pengukuran yang reliabel nilai Cronbach's Alpha (CA) minimal 0,70 (atau >0,70). Pada tabel 2 terlihat bahwa nilai reliabilitas diatas 0.7 yang artinya bahwa variabel yang digunakan reliabel.

Dalam menjawab hipotesis yang diteliti maka digunakan regresi berganda dengan alat SPSS.

\section{HASIL PENELITIAN}

Pada penelitian ini, responden yang digunakan berjumlah 175. Responden yang digunakan adalah mereka yang dalam 3 bulan terakhir membeli obat bebas painkiller.

Tabel 3 Karakteristik Responden ( $\mathrm{N}=175)$

\begin{tabular}{|c|c|c|}
\hline Data Responden & $\begin{array}{c}\text { Jumlah } \\
\text { Responden }\end{array}$ & $\begin{array}{c}\text { Persentase } \\
(\%)\end{array}$ \\
\hline \multicolumn{3}{|l|}{ Jenis Kelamin } \\
\hline Laki-laki & 80 & 45.7 \\
\hline Perempuan & 95 & 54.3 \\
\hline \multicolumn{3}{|l|}{ Umur } \\
\hline 17-27 tahun & 81 & 46.3 \\
\hline 28-38 tahun & 71 & 40.6 \\
\hline 39-49 tahun & 12 & 6.9 \\
\hline 50-60 tahun & 11 & 6.3 \\
\hline \multicolumn{3}{|l|}{ Tingkat Pendidikan Terakhir } \\
\hline SMP & 3 & 1.7 \\
\hline SMA/SMK & 79 & 45.1 \\
\hline D3 & 8 & 4.6 \\
\hline S1 & 82 & 46.9 \\
\hline S2 & 3 & 1.7 \\
\hline \multicolumn{3}{|l|}{ Pekerjaan } \\
\hline Tidak Bekerja & 11 & 6.3 \\
\hline Mahasiswa & 27 & 15.4 \\
\hline Karyawan & 124 & 70,9 \\
\hline Wiraswasta & 9 & 5.1 \\
\hline Lainnya & 4 & 2.3 \\
\hline \multicolumn{3}{|l|}{ Penghasilan rata-rata per bulan } \\
\hline$<$ Rp 4.200 .000 & 55 & 31.4 \\
\hline Rp 4.200.000- Rp 10.000.000 & 100 & 57.1 \\
\hline $\operatorname{Rp} 10.000 .001-\operatorname{Rp} 15.000 .000$ & 18 & 10.3 \\
\hline$>\operatorname{Rp} 15.000 .000$ & 2 & 1.1 \\
\hline
\end{tabular}

Menurut Tabel 3, mayoritas responden adalah perempuan yaitu sebesar 95 responden (54.3\%). Hal ini menunjukkan bahwa perempuan lebih banyak yang membeli obat bebas painkiller karena perempuan tidak dapat menahan rasa sakit, sehingga lebih banyak melakukan pengobatan sendiri dengan membeli obat bebas painkiller. 
Terbanyak kelompok umur, responden berusia 17-27 tahun sebesar 81 orang (46.3\%) yang membeli obat bebas painkiller. Pada usia ini responden akan langsung membeli obat bebas painkiller karena tidak terlalu menyukai berobat ke dokter, sehingga mereka akan langsung pergi membeli obat bebas painkiller pada saat menderita nyeri.

Untuk pendidikan, paling banyak adalah S1 sebesar 82 responden (46.9\%). Responden yang memiliki pendidikan yang tinggi cenderung untuk melakukan pengobatan sendiri. Sementara pekerjaan, paling banyak responden bekerja sebagai karyawan yaitu sebesar 124 responden (70.9\%). Pembelian obat bebas painkiller paling banyak dilakukan oleh karyawan karena beban kerja yang berat, sehingga mereka sering terserang nyeri pada bagian tubuh dan mereka cenderung terlalu kurang menyukai berobat ke dokter.

Pada penghasilan rata-rata per bulan, responden yang mendapatkan pendapatan sebesar Rp 4.200.00 - Rp 10.000.000 sebanyak 100 responden (57.1\%). Responden dengan pendapatan sebesar Rp 4.200.00 - Rp 10.000.000 cenderung untuk melakukan pengobatan sendiri dengan alasan lebih murah dan terjangkau daripada harus pergi berobat ke dokter.

\section{E. PEMBAHASAN}

Dalam menjawab hipotesis penelitian maka dilakukan uji regresi berganda. Hasil uji hipotesis terlihat pada tabel 4.

\section{Tabel 4. Hasil Uji Hipotesis}

\begin{tabular}{|c|c|c|c|c|c|}
\hline & Hipotesis & Nilai t & t-tabel & Hasil & Kesimpulan \\
\hline $\mathrm{H} 1$ & $\begin{array}{l}\text { Promotion berpengaruh } \\
\text { terhadap purchase } \\
\text { decision obat bebas } \\
\text { painkiller. }\end{array}$ & 9.845 & 1.973 & Signifikan & $\begin{array}{l}\mathrm{H}_{0} \text { ditolak, adanya pengaruh } \\
\text { antara promotion berpengaruh } \\
\text { terhadap purchase decision } \\
\text { obat bebas painkiller. }\end{array}$ \\
\hline $\mathrm{H} 2$ & $\begin{array}{l}\text { Product Quality } \\
\text { berpengaruh terhadap } \\
\text { purchase decision obat } \\
\text { bebas painkiller. }\end{array}$ & 3.809 & 1.973 & Signifikan & $\begin{array}{l}\mathrm{H}_{0} \text { ditolak, adanya pengaruh } \\
\text { antara product quality } \\
\text { berpengaruh terhadap purchase } \\
\text { decision obat bebas painkiller. }\end{array}$ \\
\hline H3 & $\begin{array}{l}\text { Price berpengaruh } \\
\text { terhadap purchase } \\
\text { decision obat bebas } \\
\text { painkiller. }\end{array}$ & 7.478 & 1.973 & Signifikan & $\begin{array}{l}\text { H0 ditolak, adanya pengaruh } \\
\text { antara price berpengaruh } \\
\text { terhadap purchase decision } \\
\text { obat bebas painkiller. }\end{array}$ \\
\hline $\mathrm{H} 4$ & $\begin{array}{l}\text { Perceived risk } \\
\text { berpengaruh terhadap } \\
\text { purchase decision obat } \\
\text { bebas painkiller. }\end{array}$ & -0.705 & 1.973 & $\begin{array}{c}\text { Tidak } \\
\text { Signifikan }\end{array}$ & $\begin{array}{l}\mathrm{H}_{0} \text { diterima, perceived risk tidak } \\
\text { berpengaruh terhadap purchase } \\
\text { decision obat bebas painkiller. }\end{array}$ \\
\hline
\end{tabular}

Berdasarkan pada Tabel 4. menunjukkan bahwa promotion berpengaruh terhadap purchase decision obat bebas painkiller. Hasil pengujian menunjukkan bahwa $\mathrm{H} 1$ diterima. Berdasarkan dari pengolahan data yang telah dilakukan, adanya pengaruh langsung pada promotion terhadap purchase decision. Artinya, semakin meningkatnya promotion, maka akan semakin meningkatnya keputusan pembelian yang dilakukan oleh 
masyarakat. Hasil ini sesuai dengan penelitian yang dilakukan oleh Rahman et al. (2017) dan Brata et al. (2017) dimana promotion memiliki pengaruh terhadap purchase decision.

Hasil uji hipotesis menunjukkan bahwa product quality berpengaruh terhadap purchase decision obat bebas painkiller diterima. Hasil pengujian ini menunjukkan bahwa $\mathrm{H} 2$ diterima. Hasil ini sesuai dengan penelitian yang dilakukan oleh Rahman et al. (2017), Brata et al. (2017) dan Suhaily et al. (2017) dimana product quality memiliki pengaruh terhadap purchase decision. Artinya, kualitas dari obat bebas painkiller semakin baik, maka akan meningkatkan keputusan pembelian dari obat bebas painkiller. Kualitas produk obat tentu diutamakan oleh konsumen saat membeli obat. Apalagi banyaknya produk obat palsu yang beredar, konsumen tentunya lebih berhati-hati dalam membeli obat. Oleh karena itu, kualitas obat tentu menjadi salah satu faktor penting dalam membeli obat-obatan.

Untuk uji H3 menunjukkan bahwa price berpengaruh terhadap purchase decision obat bebas painkiller diterima. Artinya, semakin tinggi price, maka semakin meningkatkan keputusan pembelian dari obat bebas painkiller. Hasil ini sesuai dengan penelitian yang dilakukan oleh Brata et al. (2017) dan Djatmiko \& Pradana (2016) dimana price memiliki pengaruh terhadap purchase decision. Namun, hasil penelitian Gecit et al. (2017) menunjukkan hasil yang berbeda. Dimana, hasil penelitian Gecit et al. (2017) menunjukkan tidak ada pengaruh antara price terhadap purchase decision. Perbedaan hasil dari penelitian ini dengan penelitian Gecit et al (2017) kemungkinan karena semakin tinggi harga obat bebas painkiller, maka semakin meningkat pembelian obat bebas painkiller. Masyarakat beranggapan bahwa semakin mahal obat bebas painkiller, maka efek yang dihasilkan akan semakin baik.

Pada uji $\mathrm{H} 4$ menunjukkan bahwa perceived risk berpengaruh terhadap purchase decision obat bebas painkiller ditolak. Hasil uji $\mathrm{H} 4$ menunjukkan bahwa perceived risk tidak berpengaruh terhadap purchase decision. Hasil ini tidak sesuai dengan penelitian yang dilakukan oleh Yee et al. (2011), dimana dalam penelitian Yee et al. (2011) perceived risk memiliki pengaruh terhadap purchase decision. Hal ini dikarenakan tidak adanya resiko yang ada dalam benak konsumen pada saat membeli obat bebas painkiller.

Dari hasil pengujian yang telah dilakukan, maka persamaan model regresi dapat dirumuskan sebagai berikut:

$$
P D=7.234+0.338 P O+0.142 P Q+0.275 P I-0.033 P R
$$

Keterangan:

PD : Purchasing Decision

PO : Promotion

$\mathrm{PQ} \quad$ : Product Quality

PI : Price

PR : Perceived Risk 
Dari persamaan regresi linier berganda diatas, maka pengaruh terbesar dalam purchase decicion adalah promotion. Sedangkan perceived risk tidak memiliki pengaruh terhadap purchase decision. Hal ini sesuai dengan penelitian yang dilakukan oleh Rahman et al. (2019) dan Brata et al. (2017), dimana promotion mempengaruhi purchase decision. Dalam keputusan pembelian obat bebas painkiller, konsumen tidak mempertimbangkan pengaruh product quality, price, maupun perceived risk. Product quality memiliki pengaruh terhadap purchase decision walaupun tidak sebesar promotion dan price.

Hal ini dikarenakan kualitas obat bebas tentu sesuai dengan standar yang telah ditetapkan oleh BPOM (Badan Pengawas Obat dan Makanan), sehingga quality tidak mempengaruhi dalam purchase decision obat bebas painkiller. Price memiliki pengaruh terhadap purchase decision, walaupun tidak sebesar promotion. Sedangkan perceived risk tidak memiliki pengaruh terhadap purchase decision obat bebas painkiller. Artinya masyarakat ketika melakukan purchase decision obat bebas painkiller, mereka tidak terlalu memperhatikan resiko. Hal ini dikarenakan obat bebas merupakan golongan obat bebas yang boleh dijual dimana pun. Hal ini tentu menimbulkan persepsi bagi masyarakat bahwa obat bebas tidak terlalu beresiko dibandingkan dengan obat bebas terbatas dan obat keras.

Berdasarkan persamaan regresi, maka dapat ditarik kesimpulan bahwa pada saat memperkenalkan obat bebas painkiller sebaiknya menggunakan promotion sebagai alat komunikasi dengan konsumen. Promotion akan lebih baik lagi jika dibantu dengan tenaga medis (dokter maupun apoteker). Komunikasi dengan menggunakan tenaga medis tentunya sangat membantu dalam hal promotion karena mereka lebih paham dengan efek samping dan cara penggunaan untuk obat painkiller. Sehingga konsumen merasa lebih aman dalam menggunakan obat bebas painkiller.

\section{F. KESIMPULAN DAN SARAN}

\section{Kesimpulan}

Dari hasil penelitian promotion, product quality, dan price berpengaruh terhadap purchase decision obat bebas painkiller. Namun, perceived risk tidak berpengaruh terhadap purchase decision obat bebas painkiller. Sehingga dapat disimpulkan bahwa masyarakat membeli obat bebas painkiller tanpa melihat resiko dari obat bebas yang dibeli. Hal ini dapat terjadi karena sebagai obat bebas masyarakat tidak terlalu mengkhawatirkan masalah efek samping yang akan terjadi.

\section{Saran}

Konsumen dalam melakukan pembelian produk obat bebas painkiller memperhatikan kualitas produk, harga dan promosi. Hal ini perlu menjadi perhatian bagi perusahaan 
dalam peningkatan kualitas produk, promosi dan harga. Konsumen dalam membeli obat bebas painkiller tidak memperhatikan faktor resiko, karena mereka yakin bahwa obat yang beredar sudah mendapatkan ijin BPOM. Walaupun faktor resiko tidak menjadi pertimbangan konsumen tetapi perusahaan tetap wajib menginformasikan obat bebas painkiller secara rinci dan jelas.

\section{G. DAFTAR REFERENSI}

\section{Buku}

Bauer, R. A. (1960). Consumer Behavior as Risk Taking. In Cox, D. (Ed.), Risk taking and information handling in consumer behavior (pp. 389-398). Cambridge, MA: Harvard University Press.

Clow, K.E, \& Baack, D. (2018). Integrated Advertising, Promotion, and Marketing Communications. (18 $8^{\text {th }}$ ed). Vivar, Malaysia: Pearson Education.

Ghozali, Imam. (2016). Aplikasi Analisis Multivariate dengan SPSS 23. Semarang: Badan Penerbit Universitas Diponegoro.

Hair, J., William, C., Banin, B., \& Anderson, R. (2010). Multivariate Data Analysis. 7th Edition. New Jersey: Upper Saddle River- Prentice Hall.

Kementerian Kesehatan Republik Indonesia. Laporan hasil Riset Kesehatan Dasar Indonesia (Riskesdas) tahun 2013.Jakarta: Badan Litbangkes; 2013.

Kotler, P., Amstrong, G., \& Opresnik M.O. (2018). Principle of Marketing (17 $7^{\text {th }}$ ed.). Lego, Italy: Pearson Education Limited.

Kotler, P., Keller K.L. (2016). Marketing Management (15 th ed). Unites State of America: Pearson Education Limited.

Malhotra, N.K, Nunan D., \& Birks D.F. (2017). Marketing Research (5 ${ }^{\text {th }}$ ed.). New Jersey: Pearson Education, Inc.

Orville C. W., Boyd H. W., Larreche, \& Claude J. (2005). Manajemen Pemasaran Suatu Pendekatan Strategis dengan Orientasi Global. Jakarta: Erlangga.

Sugiyono. (2017). Metode Penelitian Pendidikan Pendekatan Kuantitatif, Kualitatif, danR\&D. Bandung: Alfabeta.

Tim Penyusun Kamus Bahasa Indonesia. (2008). Kamus Bahasa Indonesia. (edisi 4). Jakarta: Pusat Bahasa Departemen Pendidikan Nasional.

Jurnal

Barnes, S. J., Bauer, H. H., Neumann, M. M., \& Huber, F. (2007). Segmenting cyberspace: a customer typology for the internet. European journal of marketing.

Boonlertvanich (2009) "Consumer buying and decision-making behavior of a digital camera in Thailand", $R U$ International Journal 3(1), 57-66.

Brata, B. H., Husani, S., \& Ali, H. (2017). The influence of quality products, price, promotion, and location to product purchase decision on Nitchi at PT. Jaya Swarasa 
Agung in Central Jakarta. Saudi Journal of Business and Management Studies, Vol 2, (4), pp 433-445.

Chen, Y., Yan, X., \& Fan, W. (2015). Examining the Effects of Decomposed Perceived

Risk on Consumer's Online Shopping Behavior: A Field Study in China. Engineering Economics, 26(3), 315-326.

Cox, D. F., \& Rich, S. U. (1964). Perceived risk and consumer decision-making-the case of telephone shopping. Journal of marketing research, Vol 1(4), pp 32-39.

Djatmiko, T. \& Pradana, R. (2016). Brand Image And Product Price; Its Impact For Samsung Smartphone Purchasing Decision. Procedia-Social and Behavioral Sciences. 219, pp 221-227.

Gecit, B.B \& Kayacan, M. (2017). Effect of Price and Brand on Purchase Decision - An Application on Turkish Smart Phone Consumers.International Conference On Eurasian Economies 2017.

Ginting, M., \& Sembiring, H. (2018). The effect of product innovation, product quality and city image on purchase decision of Uis Karo Woven Fabric. In 1st Economics and Business International Conference 2017 (EBIC 2017). Atlantis Press.

Hantoro, D, T., Pristiany, L., Athiyah, U., \& Yuda, A. (2014).Pengaruh Pengetahuan Terhadap Perilaku Swamedikasi ObatAnti-Inflamasi Nonsteroid Oral Pada Etnis Arab Di Surabaya. Jurnal Farmasi Komunitas, 1(2), 45-48.

Huff, L.C. \& Alden, D.L. (2000). A Model of Managerial Response to Sales Promotions: A Four-Country Analysis. Journal of Global Marketing. 13 (3): 7-28.

Kensei, Z., \& Todd, S. (2003). The use of price in the purchase decision. Journal of empirical generalisations in marketing science, 8(1).

Ko, H., Jung J., Kim J., \& Shim S.W. (2010). Cross-cultural differences in perceived risk of online shopping. Journal of Interactive Advertising, Vol. 4, No. 2. 20-29.

Lawson, R., \& Bhagat, P. S. (2002). The Role of Price Knowledge in Consumer Product Knowledge Structures. Psychology \& Marketing, 19(6), 551-568.

Nugraha, R., Kusumawardani, K.A. \& Octavianie, V. (2018). The Influence of Celebrity Endorsement in Instagram towards Customer Behavior and Purchase Intention in Healthy Food Diet Business. FIRM Journal of Management Studies Vol. 3 No. 2, pp. 1-24.

Rahman, H.A., \& Sitio, A. (2019). The Effect of Promotion and Product Quality Through Purchase Decision On The Customer Satisfaction Of Bohemian Project Id Products. International Journal of Engineering Technologies and Management Research. 6 (1), 55-72.

Rares, A., \& Jorie, R. J. (2015). Pengaruh Harga, Promosi, Lokasi, Citra Merek Dan Kualitas Produk Terhadap Keputusan Pembelian Konsumen Di Toko Bengkel Gaoel Manado Town Square. Jurnal Emba, 3(2), 592-604.

Singhdong, P. (2017). Analysis of Effect of Product Quality, Product Design and Distribution Channel toward Purchase Decision of Soy Milk with ABC 
company. International Journal of Applied Computer Technology and Information Systems, 6(2).

Soelasih, Y. (2014). Pengaruh Kualitas Pelayanan dan Kewajaran Tarif terhadap Nilai Konsumen serta Retensi Pelanggan untuk Penerbangan Domestik Niaga Full Services di Indonesia. KINERJA, Volume 18, No.1: Hal. 1-21.

Suhaily, L., \& Darmoyo, S. (2017). Effect Of Product Quality, Perceived Price, And Brand Image On Purchasing Decision Mediated By Customer Trust. Jurnal Management. 21 (02), 179-194.

Suhaily, L. \& Soelasih, Y. (2018). How E-Service Quality, Experiential Marketing, and Price Perception to make Repurchase Intention on On-line Shopping? The International Journal of Business Management and Technology, Volume 2 Issue 3 May-June, pp. 10-20.

Syafrida, N. (2018). Promotion and Policy Influence Prices on Consumer Purchase Decision on Football Cafe Lubukpakam. Journal of Management Science (JMAS), 1(3, Juli), 64-69.

Yee, C. J., \& San, N. C. (2011).Consumers' perceived quality, perceived value and perceived risk towards purchase decision on automobile. American Journal of Economics and Business Administration, 3(1), 47-57.

Website

Badan Pusat Statistik. (2018) Persentase Penduduk yang Mengobati Sendiri Selama Sebulan Terakhir Menurut Provinsi dan Jenis Obat yang Digunakan, 2002-2018. Diakses dari: http://www.bps.go.id/.

Katadata.co.id. (2017). 2020, Pasar Farmasi Indonesia Capai Rp 103 Triliun. Retrieved Maret 7, 2019. https://databoks.katadata.co.id/datapublish/ 2017/03/07/2020-pasarfarmasi-indonesia-capai-rp-103-triliun. 